\title{
Comportamento hídrico e crescimento do feijão vigna cultivado em solos salinizados
}

\author{
José B. M. Coelho', Maria de F. C. Barros ${ }^{2}$, Egídio Bezerra Neto ${ }^{1} \&$ Marcus M. Correa ${ }^{3}$
}

\section{RESUMO}

A salinização dos solos reduz a capacidade das plantas de absorver água o que, em geral, provoca diminuição na sua taxa de crescimento. As respostas das plantas ao estresse salino são melhor correlacionadas com o potencial osmótico do que com a condutividade elétrica do extrato de saturação do solo. Com o objetivo de avaliar os efeitos do estresse salino no crescimento, evapotranspiração e potencial osmótico foliar do feijoeiro vigna [Vigna unguiculata L. (Walp.)] conduziu-se um experimento em casa de vegetação da Universidade Federal Rural de Pernambuco (Recife, PE, Brasil). Os tratamentos constaram de um arranjo fatorial $2 \times 4$ composto de duas texturas de solo e quatro níveis de salinidade do solo $\left(4,8\right.$ e $12 \mathrm{dS} \mathrm{\textrm {m } ^ { - 1 } \mathrm { a }}$ $25{ }^{\circ} \mathrm{C}$ além da testemunha sem a adição de sais) com cinco repetições. Concluiu-se que a salinidade do solo causa redução no consumo de água, no potencial osmótico foliar, na altura das plantas, no número de folhas e na biomassa seca da parte aérea do feijoeiro vigna.

Palavras-chave: potencial osmótico, salinidade, feijão caupi

\section{Hydric behaviour and growth of cowpea cultivated in salinized soils}

\begin{abstract}
Soil salinization reduces the capacity of plants to absorb water, and in general causes decrease in plant growth. Plant responses to salt stress are better correlated with osmotic potential compared to electrical conductivity of soil saturation extract. In order to evaluate the effect of salt stress on growth, water use and leaf osmotic potential of cowpea [Vigna unguiculata L. (Walp.)], an experiment was carried out in a greenhouse of the Federal Rural University of Pernambuco (Recife-PE, Brazil). The treatments were in a factorial arrangement of $2 \times 4$, comprising of two soil textures and four levels of soil salinity $(4,8$ and 12 $\mathrm{dS} \mathrm{m}^{-1}$ at $25{ }^{\circ} \mathrm{C}$, and the control without salt addition) with five replications. It was concluded that soil salinity causes reduction in water consumption, leaf osmotic potential, plant height, number of leaves and dry biomass of shoot of cowpea.
\end{abstract}

Key words: osmotic potential, salinity, cowpea 


\section{INTRODUÇÃO}

A salinização do solo reduz a capacidade das plantas de absorver água fazendo com que haja, rapidamente, um conjunto de alterações metabólicas idênticas às provocadas pelo estresse hídrico ocasionando redução na taxa de crescimento (Munns, 2002).

Problemas de salinização são representados por solos anteriormente produtivos que se tornaram salinos devido à irrigação mal-planejada (Barros et al., 2005). Dentre os mecanismos de adaptação à salinidade a redução da área foliar e o controle na abertura dos estômatos são estratégias usadas pelas plantas para reduzir as perdas de água por transpiração resultando em uma taxa fotossintética menor, o que constitui uma das causas do reduzido crescimento das espécies sob condição de estresse salino (Flowers, 2004).

$\mathrm{Na}$ avaliação do crescimento de três cultivares de feijão vigna submetidas a estresses salinos de 2 e $10 \mathrm{dS} \mathrm{m}^{-1}$, Patel et al. (2010) constataram que houve redução na biomassa seca da parte aérea da planta com o aumento nos níveis de salinidade, da ordem de 33, 39 e 43\%, para as cultivares Akshay-102, Gomtivu-89 e Pusa Falguni, respectivamente.

Ben-Gal et al. (2009) citam que a salinidade de águas e solos tem sido frequentemente relacionada à condutividade elétrica por se tratar de um método prático e rápido de determinação, embora o potencial osmótico seja uma medida mais sensível do estado hídrico da planta. O osmômetro de pressão de vapor tem sido usado com eficiência para medir o potencial osmótico das plantas (Ball \& Osssterhuis, 2005). A redução do potencial osmótico em resposta ao déficit hídrico pode resultar de uma concentração passiva de solutos em virtude da desidratação da célula ou da acumulação ativa de solutos, esta última considerada ajuste osmótico (Patakas et al., 2002).

O feijoeiro vigna é amplamente cultivado em regiões áridas e semiáridas constituindo-se em um dos principais componentes da dieta alimentar dessas populações (Lima et al., 2007). Referida leguminosa tolera a irrigação com água salina com condutividade elétrica de até $3,3 \mathrm{dS} \mathrm{m}^{-1}$ e condutividade elétrica do extrato de saturação do solo de até $4,9 \mathrm{dS} \mathrm{m}^{-1}$ sendo considerada, portanto, uma espécie moderadamente tolerante à salinidade (Ayers \& Westcot, 1999). Contudo, o grau de tolerância do feijão vigna ao estresse salino varia entre genótipos (Dantas et al., 2002). Em estudo realizado no Vale do Gurgueia, PI, Bastos et al. (2008) contabilizaram um consumo de água do feijão vigna variedade BR 17 , de $288,5 \mathrm{~mm} \mathrm{ciclo}^{-1}$, o que corresponde a $4,1 \mathrm{~mm} \mathrm{~d}^{-1}$, para um ciclo de 70 dias. De aco rdo com Benvindo et al. (2010) a cultivar pele de moça se destaca pela precocidade, além de possuir boa potencialidade para o cultivo irrigado.

Este trabalho teve como objetivo avaliar os efeitos do estresse salino no crescimento, evapotranspiração e potencial osmótico foliar do feijoeiro vigna.

\section{Material e Métodos}

O experimento foi instalado em casa de vegetação da Universidade Federal Rural de Pernambuco localizada na latitude: $08^{\circ} 00^{\prime} 57^{\prime \prime} \mathrm{S}$, longitude: $34^{\circ} 57^{\prime} 02^{\prime \prime} \mathrm{W}$ em Recife, PE.

Os solos utilizados foram coletados em camadas superficiais $(0$ a $30 \mathrm{~cm})$ de Neossolos Flúvicos situados nos municípios de Ibimirim e Parnamirim e localizados na zona semiárida do estado de Pernambuco; amostras desses solos foram secadas ao ar, destorroadas e passadas em peneira com malha de $2 \mathrm{~mm}$.

A caracterização física dos solos foi realizada de acordo com a metodologia descrita pela EMBRAPA (1997) determinandose: a densidade do solo pelo método da proveta; a densidade de partículas pelo método do balão volumétrico; a granulometria pelo método do densímetro de Bouyoucos; a capacidade de campo pelo método do extrator de Richards a $-0,010 \mathrm{MPa}$ (solo franco-arenoso) e - $0,033 \mathrm{MPa}$ (solo franco-argiloso) e o ponto de murcha permanente pelo método do extrator de Richards (1954) a -1,5 MPa, utilizando-se amostras deformadas (Tabela 1).

A pasta saturada foi preparada de acordo com a metodologia descrita por Richards (1954) determinando-se a condutividade elétrica e os cátions solúveis: sódio e potássio, por fotometria de chama e cálcio e magnésio, por espectrometria de absorção atômica (Tabela 2); em seguida, foram determinados os valores da relação de adsorção de sódio (RAS) conforme Richards (1954).

Tabela 2. Características químicas dos extratos de saturação dos solos usados no experimento

\begin{tabular}{|c|c|c|c|c|c|c|}
\hline \multirow{2}{*}{$\begin{array}{l}\text { Classe } \\
\text { textural }\end{array}$} & \multirow{2}{*}{$\begin{array}{c}\text { CE } \\
\left(\mathrm{dS} \mathrm{m}^{-1}\right)\end{array}$} & \multicolumn{4}{|c|}{ Cátions solúveis $\left(\mathrm{mmol}_{\mathrm{c}} \mathrm{L}^{-1}\right)$} & \multirow{2}{*}{ RAS } \\
\hline & & $\mathrm{Ca}^{2+}$ & $\mathrm{Mg}^{2+}$ & $\mathrm{Na}^{+}$ & $\mathrm{K}^{+}$ & \\
\hline Franco-arenoso & 2,2 & 11,5 & 2,0 & 7,1 & 2,4 & 2,7 \\
\hline Franco-argiloso & 2,4 & 10,3 & 3,5 & 8,6 & 1,9 & 3,3 \\
\hline
\end{tabular}

As análises de fertilidade dos solos (Tabela 3) foram realizadas conforme a metodologia descrita pela EMBRAPA (1997).

Tabela 3. Caracterização da fertilidade dos solos usados no experimento

\begin{tabular}{|c|c|c|c|c|c|c|}
\hline \multirow{2}{*}{$\begin{array}{l}\text { Classe } \\
\text { textural }\end{array}$} & \multirow{2}{*}{$\mathrm{pH}$} & \multirow{2}{*}{$\begin{array}{c}P \\
\left(\mathrm{mg} \mathrm{dm}^{-3}\right)\end{array}$} & $\mathrm{Ca}^{2+}$ & $\mathrm{Mg}^{2+}$ & $\mathrm{Na}^{+}$ & $\overline{\mathbf{K}^{+}}$ \\
\hline & & & \multicolumn{4}{|c|}{$\left(\mathrm{cmol}_{\mathrm{dm}}^{-3}\right)$} \\
\hline Franco-arenoso & 7,4 & 118 & 3,95 & 1,58 & 1,10 & 0,35 \\
\hline Franco-argiloso & 7.0 & 210 & 9.30 & 1,45 & 1.30 & 1,46 \\
\hline
\end{tabular}

As unidades experimentais foram constituídas por vasos plásticos com capacidade de $3,2 \mathrm{dm}^{3}$, com duas plantas e contendo um sistema de drenagem em sua base para permitir o fluxo do lixiviado.

Tabela 1. Características físicas dos solos empregados no experimento

\begin{tabular}{|c|c|c|c|c|c|c|c|}
\hline \multirow{2}{*}{$\begin{array}{l}\text { Classe } \\
\text { Textural }\end{array}$} & \multicolumn{3}{|c|}{ Granulometria } & \multicolumn{2}{|c|}{ Densidade } & \multicolumn{2}{|c|}{ Umidade } \\
\hline & Areia & Silte & Argila & Dp & ds & ${ }^{\left({ }^{*}\right)} \mathrm{CC}$ & 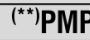 \\
\hline Franco-arenoso & 782 & 120 & 98 & 1,54 & 2,45 & 0,13 & 0,02 \\
\hline
\end{tabular}

$\mathrm{dp}$ - densidade de partículas; ds - densidade do solo; ${ }^{(*)}$ Capacidade de campo: solo franco-arenoso (-0,01 MPa); solo franco-argiloso (-0,033 MPa); $\left.{ }^{(\star \star}\right)$ Ponto de murcha permanente (-1,5 MPa) 
Para o preparo das soluções visando à salinização artificial dos solos, realizou-se um ensaio preliminar utilizando-se uma mistura de $\mathrm{NaCl}$ e $\mathrm{CaCl}_{2}$, na proporção de $2 / 3 \mathrm{de} \mathrm{NaCl}$ e $1 / 3$ de $\mathrm{CaCl}_{2}$. A concentração dos sais correspondente aos tratamentos foi estimada com base nas equações de regressão, expressas na Tabela 4.

Tabela 4. Concentração salina e condutividade elétrica (CE) do extrato da pasta saturada dos solos

\begin{tabular}{ccc}
\hline Concentração salina & \multicolumn{2}{c}{ CE do extrato da pasta saturada $\left(\mathbf{d S ~} \mathbf{~ m}^{-1}\right)$} \\
\cline { 2 - 3 } $\left.\mathbf{( g ~ k g}^{-1}\right)$ & Solo franco-arenoso & Solo franco-argiloso \\
0,0 & 2,22 & 2,40 \\
0,5 & 6,36 & 4,68 \\
1,0 & 9,75 & 7,22 \\
2,0 & 15,96 & 11,15 \\
\hline Equação & $\mathrm{Y}=2,634+6,787 \mathrm{x}$ & $\mathrm{Y}=2,526+4,385 \mathrm{x}$ \\
$\mathrm{R}^{2}$ & 0,99 & 0,99 \\
\hline
\end{tabular}

O experimento constou de um arranjo fatorial $2 \times 4$, sendo duas classes texturais de solo e quatro níveis de salinidade do solo. As classes texturais de solos foram franco-arenoso e franco-argiloso e os níveis de salinidade dos solos foram equivalentes às condutividades elétricas (CE) de 4, 8 e $12 \mathrm{dS}$ $\mathrm{m}^{-1}$, além da testemunha sem a adição de sais. Os potenciais osmóticos $\left(\Psi_{0}\right)$ correspondentes às condutividades elétricas utilizadas estão expressos na Tabela 5.

Tabela 5. Detalhamento dos tratamentos utilizados nos experimentos

\begin{tabular}{cccccl}
\hline $\begin{array}{c}\text { Classes } \\
\text { texturais }\end{array}$ & Variáveis & \multicolumn{4}{c}{ Níveis de salinidade } \\
\multirow{2}{*}{ Franco-arenoso } & $\left.\mathrm{CE}(\mathrm{dS} \mathrm{m})^{-1}\right)$ & 2,2 & 4,0 & 8,0 & 12,0 \\
& $\Psi_{0}(\mathrm{MPa})$ & $-0,012$ & $-0,049$ & $-0,133$ & $-0,215$ \\
\hline \multirow{2}{*}{ Franco-argiloso } & $\left.\mathrm{CE}(\mathrm{dS} \mathrm{m})^{-1}\right)$ & 2,4 & 4,0 & 8,0 & 12,0 \\
& $\Psi 0(\mathrm{MPa})$ & $-0,016$ & $-0,049$ & $-0,133$ & $-0,215$ \\
\hline
\end{tabular}

A cultura teste utilizada foi o feijão vigna [Vigna unguiculata L. (Walp.)], cultivar pele de moça, cedida pelo Instituto Agronômico de Pernambuco (IPA). O delineamento experimental adotado foi o inteiramente casualizado, com 5 repetições, totalizando 40 unidades experimentais.

Inicialmente, foi feito o preenchimento dos vasos colocando-se $2,8 \mathrm{dm}^{3}$ de solo, seguido da salinização artificial dos solos. Em cada vaso foram semeadas seis sementes de feijão vigna; após a germinação, que ocorreu entre 3 e 5 dias depois da semeadura, foi feito o desbaste deixando-se apenas duas plantas por vaso, o que ocorreu cerca de 7 dias após a germinação.

A irrigação da cultura foi atendida mediante a aplicação de volumes de água destilada, diariamente para o solo de textura franco-arenosa e a cada dois dias para o solo de textura francoargilosa, até que ocorresse o início da drenagem do lixiviado em cada vaso. Durante toda a condução do experimento os líquidos drenados foram reutilizados nas parcelas correspondentes, com vista à reposição dos sais.

Com base na análise de fertilidade dos solos e com o objetivo de corrigir carências nutricionais foram aplicados, por vaso, $30 \mathrm{e}$ $50 \mathrm{~mL}$ da solução completa de Hoagland e Arnon, para os solos franco-argiloso e franco-arenoso, respectivamente.
A colheita das plantas ocorreu aos 28 dias após a semeadura, ocasião em que as plantas do tratamento testemunha apresentavam quatro folhas definitivas expandidas.

A medição da água evapotranspirada foi feita aos: 7, 14, 21 e 28 dias após a semeadura; no dia anterior à medição, os solos foram irrigados até o início da sua drenagem; vinte e quatro horas após aplicaram-se volumes conhecidos de água suficientes para proporcionar nova drenagem nos recipientes coletores; esperou-se a drenagem cessar e com o auxílio de uma proveta foram feitas as medições dos volumes drenados; a diferença de leitura entre os volumes aplicados e drenados correspondeu ao volume de água armazenado no solo de cada parcela.

A conversão dos valores de volume de água aplicados em lâmina de água foi realizada com base na área da superfície do vaso, com $188,5 \mathrm{~cm}^{2}$.

O potencial osmótico foliar foi determinado utilizando-se folhas do terço médio das plantas; no tratamento testemunha, devido à maior disponibilidade de folhas, também se determinou o potencial osmótico foliar em função da localização da folha na planta, correspondendo à seguinte notação: [1] = folhas cotiledonares e [2], [3], [4] e [5] = folhas secundárias considerando-se o sentido da folha mais velha para a mais nova (Figura 1).
A.

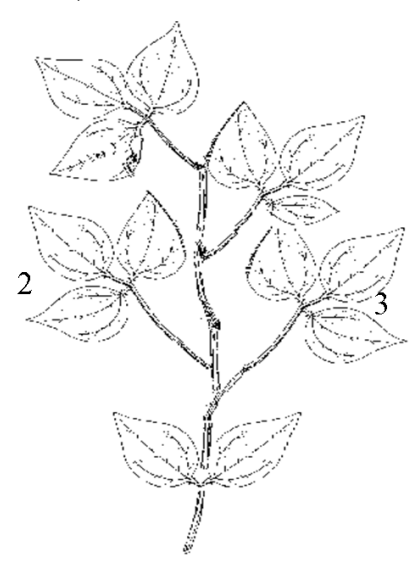

B.

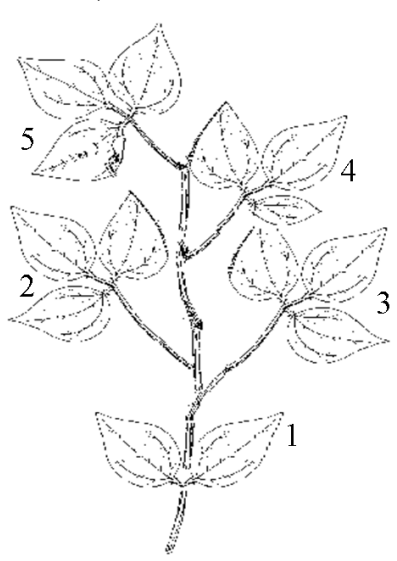

Figura 1. Localização das folhas utilizadas para determinação do potencial osmótico (A) no terço médio das plantas e (B) de acordo com o posicionamento da folha na planta

Para a extração da seiva foliar do feijão vigna folhas foram colocadas dentro de tubo de Eppendorf, previamente perfurado na base, o qual funcionou como um minifiltro. Com um bastão de vidro fez-se a prensagem do tecido foliar ocasionando a extração da seiva que foi coletada em outro tubo de Eppendorf; em seguida, o extrato foi centrifugado a $25.000 \mathrm{~g}$ durante $10 \mathrm{~min}$ a $4{ }^{\circ} \mathrm{C}$; uma alíquota de $10 \mu \mathrm{L}$ do sobrenadante foi utilizada para determinação da osmolalidade do tecido foliar do feijão usandose um osmômetro de pressão de vapor, modelo Wescor 5520.

Os valores de potencial osmótico foram obtidos a partir da osmolalidade $\left(\mathrm{mmol} \mathrm{kg}^{-1}\right)$ da seiva do tecido foliar, mediante o uso da equação de Van't Hoff (Reichardt \& Timm, 2004) sendo em seguida convertidos em MPa.

A altura das plantas foi determinada com uma fita métrica medindo-se a distância vertical entre a superfície do solo e 
a inserção do caule com a última folha. O número de folhas foi obtido mediante a contagem das folhas completamente expandidas e a biomassa seca foi determinada após a secagem da matéria fresca da parte aérea (folhas e caule) em estufa a 65 ${ }^{\circ} \mathrm{C}$ até a obtenção de massa constante.

\section{Resultados E Discussão}

Não houve efeito significativo da interação entre texturas de solos e os níveis de sais sobre nenhuma das variáveis estudadas no feijoeiro vigna (Tabela 6).

Tabela 6. Valores de $\mathrm{F}$ resultantes das análises de variância

\begin{tabular}{|c|c|c|c|c|c|}
\hline FV & ETc & $\Psi 0$ & $\mathrm{H}$ & NF & $\overline{B S P A}$ \\
\hline Text. Solos (F1) & $10,1^{\star \star}$ & $21,9 * \star$ & $0,8^{\mathrm{NS}}$ & $30,2^{\star \star}$ & $3,9^{\mathrm{NS}}$ \\
\hline Niveis Sais (F2) & $23,9 * \star$ & 104,9 ** & $207,4^{* *}$ & $99,2 * \star$ & $28,4^{* *}$ \\
\hline Int. F1 x F2 & $0,6^{\mathrm{NS}}$ & $0,7^{\mathrm{NS}}$ & $2,7^{\mathrm{NS}}$ & $0,4^{\mathrm{NS}}$ & $0,6^{\mathrm{NS}}$ \\
\hline
\end{tabular}

ETc - evapotranspiração da cultura; $\Psi_{0}$ - potencial osmótico foliar; $\mathrm{H}$ - altura da planta; $\mathrm{NF}$ - número de folhas; BSPA - biomassa seca da parte aérea

** Significante a nível de 0,01; NS - não significativo

Os resultados mostram que em todos os períodos avaliados houve respostas lineares e decrescentes da evapotranspiração da cultura (ETc) em função dos níveis de salinidade, para ambos os solos (Figura 2).

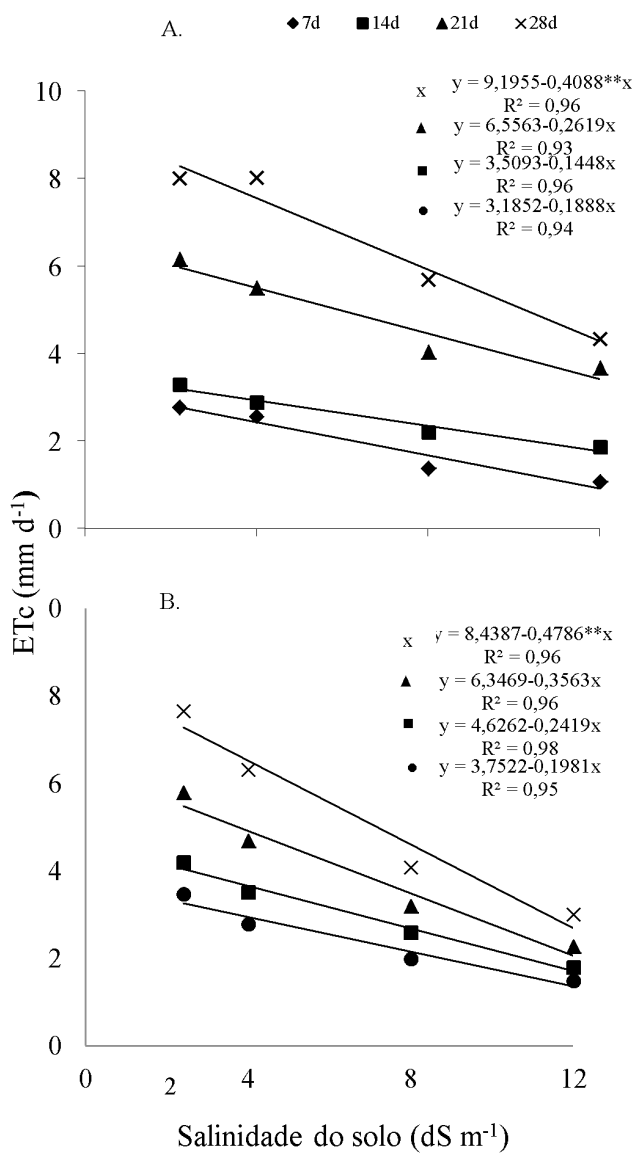

Figura 2. Evapotranspiração do feijoeiro vigna (ETc), em função da salinidade dos solos (A) franco-arenoso e (B) franco-argiloso aos 7, 14, 21 e 28 dias após a semeadura
Aos 28 dias após a semeadura no solo franco-arenoso, a maior lâmina evapotranspirada no feijão foi verificada no tratamento testemunha $\left(8,01 \mathrm{~mm} \mathrm{~d}^{-1}\right)$ e a menor $(4,34 \mathrm{~mm}$ $\left.\mathrm{d}^{-1}\right)$ no tratamento com salinidade do solo igual a $12 \mathrm{dS} \mathrm{m}^{-1}$, o que correspondeu a uma redução de 45,8\% (Figura 2A). Comportamento semelhante foi observado para o solo francoargiloso cujo maior valor evapotranspirado pelo feijão foi verificado no tratamento testemunha $\left(7,66 \mathrm{~mm} \mathrm{~d}^{-1}\right)$ enquanto no tratamento com salinidade do solo igual a $12 \mathrm{dS} \mathrm{m}^{-1}$, a ETc foi de $3,02 \mathrm{~mm} \mathrm{~d}^{-1}$, correspondendo a uma redução de $60,5 \%$ (Figura 2B).

Devido à salinidade natural dos solos das testemunhas ser equivalente a 2,2 e 2,4 $\mathrm{dS} \mathrm{m}^{-1}$, para os solos de texturas francoarenosa e franco-argilosa, respectivamente, observa-se, nos gráficos da Figura 2, que houve pequena diferença em consumo de água pela cultura.

Avaliando o consumo de água do feijão vigna em condições salinas, Souza (2007) também constatou redução na evapotranspiração a qual foi reduzida em $47,3 \%$ quando a salinidade do solo passou de 0,5 para $8,0 \mathrm{dS} \mathrm{m}^{-1}$.

Analisando os dados da Figura 2 pode-se admitir que a redução da evapotranspiração da cultura está relacionada com a ação do componente osmótico que, por sua vez, dificulta a absorção de água pela planta; como consequência, o feijoeiro teve seu crescimento afetado pelos níveis de salinidade do solo apresentando alterações morfológicas (folhas menores e menor número de folhas) que também contribuíram para um consumo menor de água, pela planta.

Os resultados obtidos na pesquisa sugerem que, com a quantidade de água aplicada na irrigação do feijoeiro vigna em áreas salinizadas, deve-se considerar o componente osmótico visando otimizar os custos de produção, além de evitar a redução da fertilidade do solo por lixiviação excessiva.

Houve uma resposta linear e decrescente do potencial osmótico foliar do feijão vigna em função da salinidade dos solos (Figura 3). Os coeficientes de determinação $\left(\mathrm{R}^{2}\right) \mathrm{de}$ 0,99 e 0,97 para os solos franco-arenoso e franco-argiloso, respectivamente, mostram alta relação entre essas variáveis. No solo franco-arenoso o maior potencial osmótico $(-0,648$ $\mathrm{MPa})$ foi observado no tratamento testemunha $\left(2,2 \mathrm{dS} \mathrm{m}^{-1}\right)$

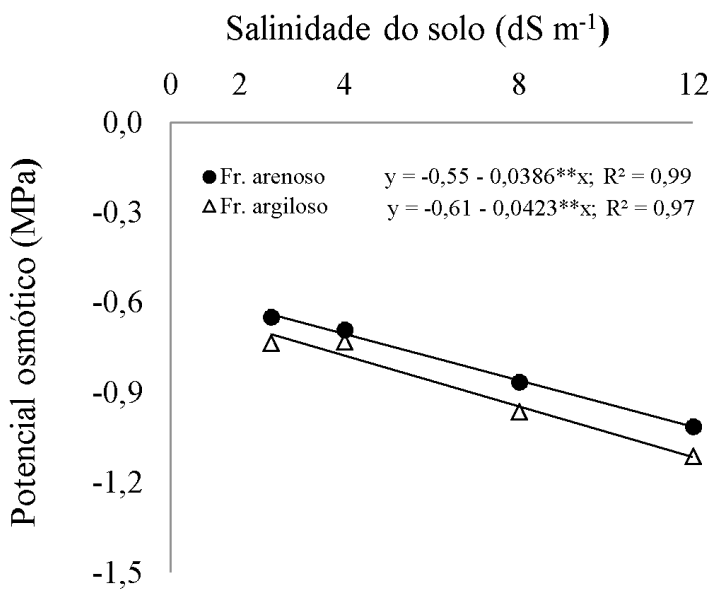

Figura 3. Potencial osmótico foliar do feijoeiro vigna em função da salinidade dos solos franco-arenoso e franco-argiloso 
enquanto no tratamento com maior salinidade $\left(12 \mathrm{dS} \mathrm{m}^{-1}\right)$ o potencial osmótico foliar do feijão apresentou valor de $-1,012$ $\mathrm{MPa}$, que corresponde a uma redução de $56,2 \%$. No solo francoargiloso o maior potencial osmótico (-0,734 MPa) também foi verificado no tratamento com a menor salinidade do solo enquanto no tratamento mais salino o potencial osmótico foliar do feijão apresentou valor de $-1,110 \mathrm{MPa}$, que corresponde a uma redução de 51,3\%.

Os valores de potencial osmótico observados neste estudo revelaram que no tratamento com maior salinidade do solo ocorreu grande redução no status energético da água na planta. Mesmo com os níveis salinos aplicados e a intensa demanda evaporativa observada no ambiente da casa de vegetação, a cultura foi capaz de manter seus processos metabólicos, embora em níveis menores, através de mecanismos que evitam a perda de água.

Durante a aplicação do estresse salino no feijão as folhas das plantas submetidas às salinidades do solo equivalentes a 8 e $12 \mathrm{dS} \mathrm{m}^{-1}$, sempre se apresentaram expandidas, sugerindo ótimos níveis de turgescência. Esses resultados têm respaldo em trabalho desenvolvido por Souza et al. (2011) ao observarem diminuição do potencial hídrico em folhas de feijoeiro vigna com o aumento da salinidade $(200 \mathrm{mM}$ de $\mathrm{NaCl})$. Hasegawa et al. (2000) citam redução do potencial osmótico devido à alta acumulação de $\mathrm{Na}^{+}, \mathrm{Cl}^{-}$e $\mathrm{K}^{+}$. Souza et al. (2011) mencionam que os solutos orgânicos, como os carboidratos solúveis totais, também contribuem para a redução do potencial osmótico das folhas de feijão vigna em ambientes salinos, submetidos a 200 $\mathrm{mM}$ de $\mathrm{NaCl}$.

O potencial osmótico foliar em relação ao posicionamento da folha na planta é mostrado na Figura 4. Os dados obtidos indicam que houve uma redução progressiva do potencial osmótico em função da idade da folha na planta de forma que, quanto mais nova a folha menor foi o seu potencial osmótico. O potencial osmótico $(-0,686 \mathrm{MPa})$ observado na folha mais velha (cotiledonar) foi reduzido em $52 \%$ em relação ao potencial osmótico da folha apical [5] (-1,042 MPa).

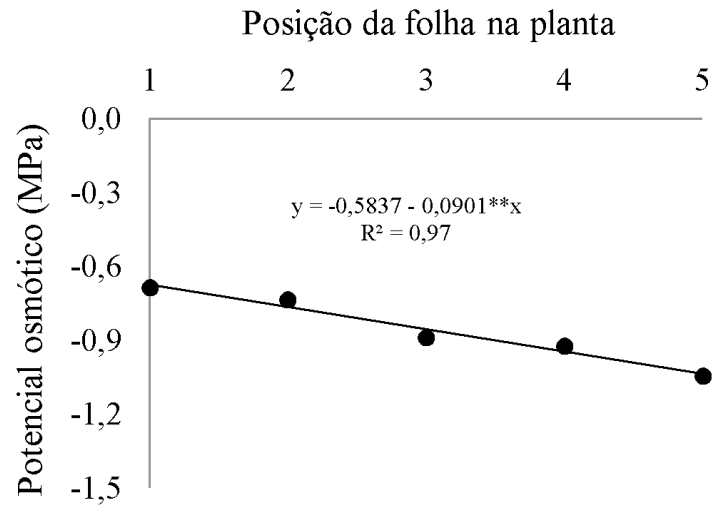

Figura 4. Potencial osmótico foliar de feijoeiros vigna de acordo com o posicionamento da folha na planta, no tratamento testemunha, no solo franco-arenoso, aos 28 dias após a semeadura

Considerando que a média dos potenciais osmóticos foliares verificados na planta foi de $-0,854 \mathrm{MPa}$, o qual se aproxima mais do potencial osmótico da folha [3] (-0,886 MPa), sugere- se o uso do valor obtido no terço médio da planta como o mais representativo do potencial osmótico foliar do feijoeiro vigna.

Para o solo franco-arenoso a maior altura do feijoeiro foi observada no tratamento testemunha $(93,9 \mathrm{~cm})$ enquanto no tratamento com salinidade do solo igual a $12 \mathrm{dS} \mathrm{m}^{-1}$, o feijoeiro apresentou 23,6 cm de altura, que corresponde a uma redução de $74,8 \%$. Comportamento semelhante foi verificado para o solo franco-argiloso no qual a altura do feijoeiro no tratamento testemunha $(99,8 \mathrm{~cm})$ foi reduzida em $84,0 \%$ em relação à altura da planta no tratamento mais salino (Figura 5). A redução do crescimento do feijoeiro vigna sob estresse salino pode ser explicada pela diminuição do potencial osmótico da solução do solo, a qual ocasiona maior dificuldade de absorção de água, como também pela possibilidade da ocorrência de toxicidade iônica em função do acúmulo excessivo de determinados íons.

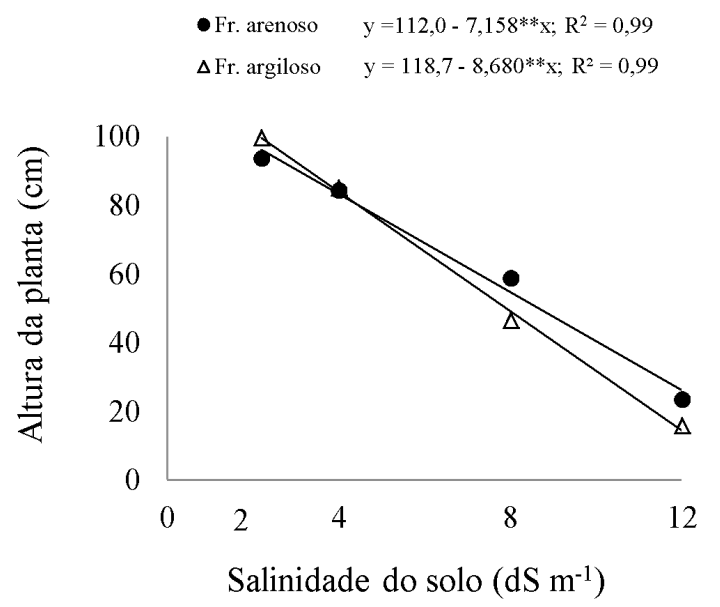

Figura 5. Relação entre a altura do feijoeiro vigna e a salinidade dos solos franco-arenoso e franco-argiloso aos 28 dias após a semeadura

Esses resultados estão em conformidade com os obtidos por Lima et al. (2007) os quais observaram diminuição na altura do feijoeiro vigna em cerca de $42,86 \%$ nas plantas irrigadas com água contendo salinidade de $5,0 \mathrm{dS} \mathrm{m^{-1 }}$, em comparação com o tratamento testemunha, após 45 dias da semeadura. Taffouo et al. (2009) também constataram reduções nas alturas de feijoeiros vigna (cultivares IT97K-573-1-1; IT97K-573-2-1; IT98K-615-6-1; IT00K-218-22; IT03K-337-6; IT04K-227-2; IT04K-321-2; Mouola GG; Mouola PG), quando foram submetidos à salinidade de $50 \mathrm{mM}\left(\cong 6,5 \mathrm{dS} \mathrm{m}^{-1}\right)$ em relação ao tratamento testemunha (sem a adição de sais).

A relação entre a salinidade do solo e o número de folhas do feijoeiro vigna é apresentada na Figura 6. Houve uma relação negativa entre os níveis de salinidade do solo e a quantidade de folhas da planta, para ambos os solos. Para o solo francoarenoso as plantas do tratamento testemunha apresentaram 4,2 folhas enquanto no tratamento mais salino $\left(\mathrm{CE}=12 \mathrm{dS} \mathrm{m}^{-1}\right)$ as plantas produziram apenas 2,1 folhas, correspondendo a uma redução de $50 \%$. Comportamento semelhante foi observado para o solo franco-argiloso, em que houve uma redução de $59 \%$ na quantidade de folhas quando se comparou o tratamento testemunha com o tratamento mais salino. Salienta-se que as plantas foram avaliadas aos 28 dias após a semeadura, porém a tendência de redução do número de folhas é esperada ao longo 
de todo o ciclo da cultura. A diminuição no número de folhas no feijão vigna pode estar relacionada ao menor crescimento da planta devido à restrição no processo de absorção; como consequência, ocorre redução do fluxo de água no sentido solo-planta-atmosfera ocasionando alterações morfológicas e anatômicas na planta. Silva et al. (2009) também verificaram redução no número de folhas no feijão vigna $(48,7 \%)$ à medida em que se aumentou o nível salino da água da irrigação, de 0,5 para $5,0 \mathrm{dS} \mathrm{m}^{-1}$.

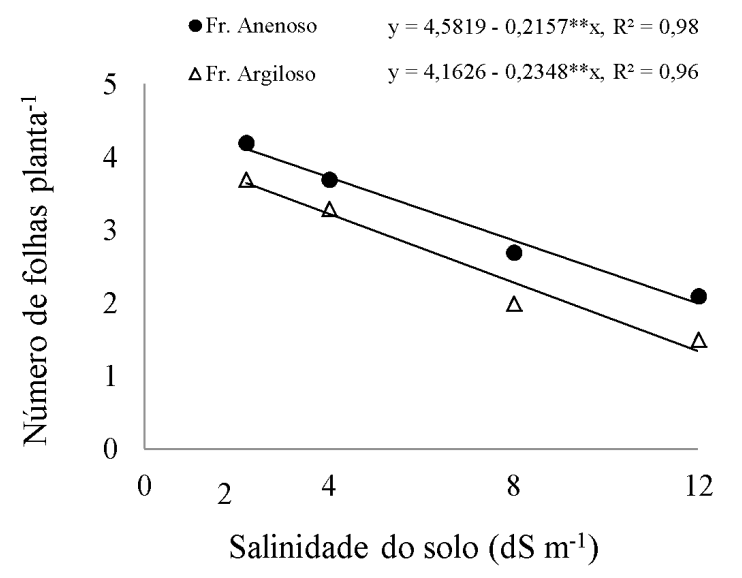

Figura 6. Número de folhas expandidas em feijoeiros vigna em função da salinidade dos solos franco-arenoso e franco-argiloso, aos 28 dias após a semeadura

A relação entre a salinidade do solo e a biomassa seca da parte aérea (BSPA) do feijoeiro vigna é apresentada na Figura 7; para ambos os solos houve resposta linear dos níveis de salinidade do solo influenciando, de forma negativa, a biomassa seca da parte aérea da planta; para o solo franco-arenoso verifica-se que a maior biomassa seca da parte aérea do feijoeiro foi observada no tratamento testemunha $(0,96 \mathrm{~g})$ enquanto no tratamento com salinidade do solo igual a $12 \mathrm{dS} \mathrm{m}^{-1}$, o feijoeiro apresentou $0,34 \mathrm{~g}$ de massa seca, que corresponde a uma redução de $64,5 \%$. Comportamento semelhante foi verificado para o solo franco-argiloso no qual a BSPA do feijoeiro no

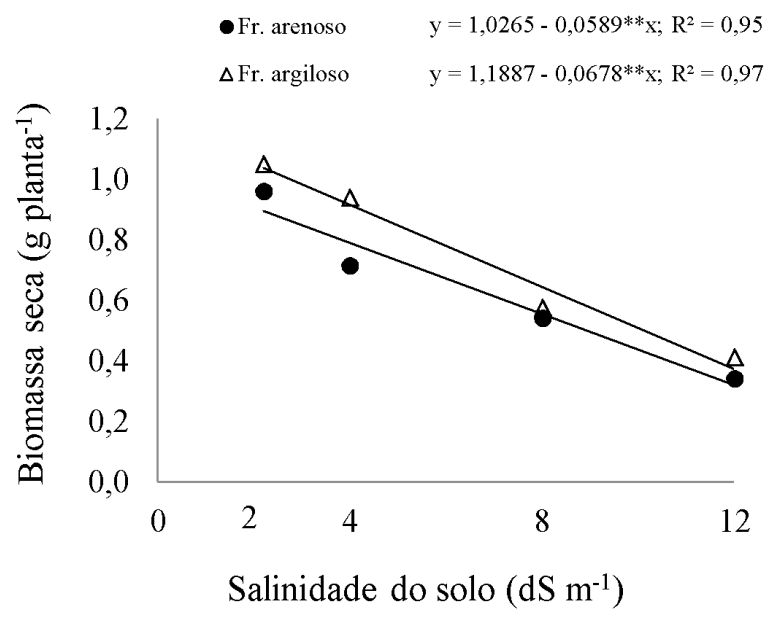

Figura 7. Biomassa seca da parte aérea de feijoeiros vigna em função da salinidade dos solos francoarenoso e franco-argiloso, aos 28 dias após a semeadura tratamento testemunha $(1,05 \mathrm{~g})$ foi reduzida em $60,7 \% \mathrm{em}$ relação à BSPA da parte aérea, no tratamento mais salino.

A redução da biomassa seca da parte aérea da planta verificada com o aumento da salinidade do solo ocorreu devido ao efeito osmótico dos sais em torno das raízes e do possível acúmulo de íons potencialmente tóxicos $\left(\mathrm{Na}^{+} \mathrm{e} \mathrm{Cl}-\right)$ nos tecidos foliares; como consequência, a planta passou a exercer um controle maior na abertura dos estômatos para evitar a excessiva perda de água por transpiração. Entretanto, o fechamento dos estômatos diminui a difusão do $\mathrm{CO}_{2}$ para dentro das células com consequente redução na taxa de fotossíntese e crescimento da planta (Souza et al., 2011). O menor crescimento do feijoeiro funciona como mecanismo adaptativo à condição de ambiente salino proporcionando condições para que a planta mantenha suas atividades vitais, mesmo que de forma limitada.

A cultivar Quarentinha de feijão vigna também teve sua biomassa seca da parte aérea reduzida com o aumento da salinidade do solo. Verificou-se redução de $66,94 \%$ na biomassa seca quando a mesma foi irrigada com água com salinidade de 5,0 dS m m. $^{-1}$ em comparação com a testemunha (Lima et al., 2007).

\section{Conclusão}

O aumento da salinidade do solo provoca redução na evapotranspiração, no potencial osmótico foliar, na altura da planta, no número de folhas e na biomassa seca da parte aérea do feijoeiro vigna.

\section{Agradecimento}

Ao Instituto Agronômico de Pernambuco (IPA) pelo fornecimento das sementes de feijão vigna.

\section{Literatura Citada}

Ayers, R. S.; Westcot, D. W. A qualidade de água na agricultura. 2.ed. Campina Grande: UFPB, 1999. 153p. FAO Irrigação e Drenagem

Ball, R. A.; Oosterhuis, D. M. Measurement of root and leaf osmotic potential using the vapor-pressure osmometer. Environmental and Experimental Botany, v.53, p.77-84, 2005.

Barros, M. de F. C.; Fontes, M. P. F.; Alvarez, V. H.; Ruiz, H. A. Aplicação de gesso e calcário na recuperação de solos salino-sódicos do Estado de Pernambuco. Revista Brasileira de Engenharia Agrícola e Ambiental, v.9, p.320326, 2005.

Bastos, E. A.; Ferreira, V. M.; Silva, C. R.; Andrade Júnior, A. S. Evapotranspiração e coeficiente de cultivo do feijãocaupi no Vale do Gurguéia, Piauí. Irriga, v.13, p.182-190, 2008.

Ben-Gal, A.; Borochov-Neon, H.; Yermiyahu, U.; Shani, U. Is osmotic potential a more appropriate property than electrical conductivity for evaluating whole-plant response to salinity? Environmental and Experimental Botany, v.65, p.232-237, 2009. 
Benvindo, R. N.; Silva, J. A. L.; Freire Filho, F. R.; Almeida, A. L. G.; Oliveira, J. T. S.; Bezerra, A. A. C. Avaliação de genótipos de feijão-caupi de porte semi-prostrado em cultivo de sequeiro e irrigado. Comunicata Scientiae, v.1, p.23-28, 2010.

Dantas, J. P.; Marinho, F. J. L.; Ferreira, M. M. M.; Amorim, M. S. N.; Andrade, S. I. O.; Sales, A. E. Avaliação de genótipos de feijão-de-corda sob salinidade. Revista Brasileira de Engenharia Agrícola e Ambiental, v.6, p.425430, 2002.

EMBRAPA - Empresa Brasileira de Pesquisa Agropecuária. Manual de métodos de análises de solo. 2.ed. Rio de Janeiro: Ministério da Agricultura e do Abastecimento, 1997. 212p.

Flowers, T. J. Improving crop salt tolerance. Journal of Experimental Botany, v.55, p.307-319, 2004.

Hasegawa, P. M.; Bressan, R. A.; Zhu, J. K.; Bonert, H. J. Plant cellular and molecular responses to high salinity. Annual Review of Plant Physiology and Plant Molecular Biology, v.51, p.463-499, 2000.

Lima, C. J. G. de S.; Oliveira, F. de A. de; Medeiros, J. F. de; Oliveira, M. K. T.; Almeida Júnior, A. B. de. Resposta do feijão caupi a salinidade da água de irrigação. Revista Verde de Agroecologia e Desenvolvimento Sustentável, v.2, p.79-86, 2007.

Munns, R. Comparative physiology of salt and water stress. Plant, Cell and Environment, v.25, p.239-250, 2002.
Patakas, A.; Nikolaou, N; Zioziou, E.; Radoglou, K.; Noitsakis, B. The role of organic solute and ion accumulation in osmotic adjustment in drought-stressed grapevines. Plant Science, v.163, p.361-367, 2002.

Patel, P. R.; KajalII, S. S.; PatelI, V. R.; Patel, V. J.; KhristiII, S. M. Impact of saline water stress on nutrient uptake and growth of cowpea. Brazilian Journal of Plant Physiology, v.22, p.43-48, 2010.

Reichardt, K; Timm, L. C. Solo, Planta e atmosfera: Conceitos, processos e aplicações. São Paulo: Manole, 2004. 478p.

Richards, L. A. Diagnosis and improvement of saline and alkali soils. Washington: US Department of Agriculture, 1954. 160p. Agriculture Handbook, 60.

Silva, F. E. O. da; Maracajá, P. B.; Medeiros, J. F. de; Oliveira, F. de A.; Oliveira, M. K. T. de. Desenvolvimento vegetativo do feijão caupi irrigado com água salina em casa de vegetação. Revista Caatinga, v.22, p.156-159, 2009.

Souza, C. H. C. Análise da tolerância à salinidade em plantas de sorgo, feijão-de-corda e algodão. Fortaleza: UFC, 2007. 73p. Dissertação Mestrado

Souza, R. P.; Machado, E. C.; Silveira, J. A. G.; Ribeiro, R. V. Fotossíntese e acúmulo de solutos em feijoeiro caupi submetido à salinidade. Pesquisa Agropecuária Brasileira, v.46, p.587-592, 2011.

Taffouo, V. D.; Kouamou, J. K.; Ngalangue, L. M. T.; Ndjeudji, B. A. N. Effects of salinity stress on growth, ions partitioning and yield of some cowpea (Vigna unguiculata L. Walp.) Cultivars. International Journal of Botany, v.5, p.135-143, 2009. 